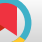

\title{
Creatine Phosphokinase and Urea as Biochemical Markers of Muscle Injuries in Professional Football Players
}

\author{
Juan J Osorio ${ }^{1,2}$, Edgar A Méndez ${ }^{3}$, Daniel Aguirre-Acevedo ${ }^{4}$, Jorge Osorio-Ciro ${ }^{1,5}$, Juan C Calderón ${ }^{6}$ \\ and Jaime A Gallo-Villegas ${ }^{1,2,5,{ }^{*}}$ \\ ${ }^{1}$ Sports Medicine Postgraduate Program, Faculty of Medicine, University of Antioquia, Medellín, Colombia \\ ${ }^{2}$ SICOR Center, Medellín, Colombia \\ ${ }^{3}$ Deportivo Independiente Medellín, Medellín, Colombia \\ ${ }^{4}$ Academic Group of Clinical Epidemiology, University of Antioquia, Medellín, Colombia \\ ${ }^{5}$ GRINMADE Research Group, Faculty of Medicine, University of Antioquia, Medellín, Colombia \\ ${ }^{6}$ Physiology and Biochemistry Research Group-PHYSIS, Faculty of Medicine, University of Antioquia, Medellín, Colombia \\ "Corresponding author: Sports Medicine Postgraduate Program, Faculty of Medicine, University of Antioquia, 70th St., No. 52-21, Medellín, Colombia. Tel: +57-42196030, Fax: \\ +57-42630253, Email: jaime.gallo@udea.edu.co
}

Received 2017 August 16; Revised 2018 September 04; Accepted 2018 September 14.

\begin{abstract}
Background: Although biochemical markers have been used to monitor training loads (TL), it is unknown if they can be used to predict muscle injuries (MI) in professional football (soccer) players (PFP).

Objectives: To evaluate the relationship between the incidence of MI, serum concentration of creatine phosphokinase (CPK) and urea, as well as TL in PFP.

Methods: Twenty-three PFP from a Colombian first-division team were enrolled in a retrospective cohort study. CPK, urea, TL and new MI were measured during 19 weeks. CPK and urea serum levels within 4 weeks before a diagnosed MI were compared to those measured preseason. CPK and urea relationship with TL were analyzed using a mixed-effects model.

Results: The subjects had an age of $25.3 \pm 4.2$ years. Nine subjects presented with MI during follow-up, $66.6 \%$ of which were localized to hamstrings. Serum CPK and urea profiles were constructed for each player along the season. Injured players had a significant elevation of these markers within 4 weeks before the injury was clinically evident when compared to their own preseason values. Expected individual increases in CPK and urea according to TL during the season were estimated.

Conclusions: Since CPK and urea values rose several weeks before the MI became overt, constructing CPK and urea profiles for each player during the whole preseason and season may help identify peaks in their concentration as early markers of MI. A tight biochemical control of training may become a preventive strategy for MI, but the use of published reference values is discouraged.
\end{abstract}

Keywords: Creatine Phosphokinase (CPK), Urea, Muscle Injuries, Sports Injuries, Football, Soccer, Biological Markers

\section{Background}

Muscle injuries (MI) incidence is increasing among high performance football (soccer) players $(1,2)$. They represent over $15 \%$ of all sports injuries $(1,3-6)$. Almost half of MI can be classified as moderate and serious, which lead to greater athlete absence rate in training sessions and competitions $(1,7)$.

Multiple strategies have been designed to reduce injury incidence, including improvement of athletic capabilities and use of several external devices (8-11). FIFA has proposed several injury prevention programmes which have shown good results $(8,11)$.

However, from the medical, sports and economical points of view, it would be more interesting to have a way to predict and then prevent the occurrence of MI.

Several biochemical markers have been shown to increase in relation to actual muscle damage, but they have not been studied in relation to the minimal tissue changes which may occur before the onset of clinically evident MI (12-14). In the biomedical control of training, creatine phosphokinase (CPK) and urea have received more attention as indicators of muscular stress and their measurement is accessible in most settings.

CPK is a well-known globular, dimeric enzyme that helps maintain stable adenosine triphosphate concentration inside a working muscle fibre $(13,15,16)$. Of our interest is the CPK-MM isoform, which is found in the cytoplasm of skeletal muscle. This isoenzyme appears in the plasma after a rupture of a muscle fibre membrane as in the case 
of sports-related MI or other medical conditions $(13,17,18)$. It also increases in plasma as a result of muscle adaptation resulting from training and an increased membrane permeability $(13,17,19)$.

Urea is a product of the deamination of amino acids in the muscle and has been used as a workload marker, mainly for long lasting high intensity exercises (20).

A wealth of data on the physiological values of CPK and urea and the kinetics of its appearance in and disappearance from the plasma has been published (19-21). There is still a search for specific reference values regarding the type of sport (21-23). These results are subject to great variability because of the influence of race, age, gender, amount of muscle mass, altitude above the sea level, training load, etc. $(13,17,19,20,24)$ Therefore, the ranges and cutoff values proposed as indicative of muscle stress are ample $(20,21)$, do not have high enough sensitivity and specificity for any outcome, and are difficult to extrapolate from one population to another. Moreover, they have never been reliably proposed as predictors of MI in football players.

Since minimal, subclinical muscle damage may occur prior to an overt MI, we hypothesize that by measuring CPK and urea during the whole season, we will identify alterations in their values several days previous to when a MI is fully established. This will allow their use as markers for the appearance of a future MI and help in early prevention of these injuries, beside general reference values.

Then, the objective of the study was to describe CPK and urea plasma concentrations in football players during a whole season and to relate their kinetics to the incidence of MI focused on the importance of individualisation of follow-up.

\section{Methods}

\subsection{Population and Study Design}

A retrospective cohort study was carried out. Twentythree adult, male, professional football players of a team established in the city of Medellín, Colombia, were enrolled. They participated in the first division of the football national league in the 2010 July-November season. Data was collected in 2012. Follow-up of the subjects was done by the medical staff of the football team.

Athletes who had any type of heart or lung disease, diabetes mellitus, smoking habit, alcohol intake or intake of any other type of psychoactive substance, use of medication, musculoskeletal injuries in the first week of the preseason and a medical disability which could impede participation in training sessions and competitions were excluded.
All procedures involving humans in this study were in accordance with the 1964 Declaration of Helsinki and the resolution number 8430 of 1993 by the National Ministry of Health of Colombia, and were approved by the Bioethics Committee of the University of Antioquia, Colombia (minutes 004 from March 2017). No informed consent was obtained because it is not required for this type of study.

\subsection{Medical History and Physical Examination: Player's Base- line Information}

A complete medical history and physical examination was performed. Age and playing position were always recorded. Weight was measured using a calibrated scale (Beurer Living, Germany) and height using a stadiometer (Stanley Powerlock, USA). Body mass index (BMI) was calculated as BMI $=$ weight $(\mathrm{kg}) /$ height ${ }^{2}\left(\mathrm{~m}^{2}\right)$, and the percentage of body fat was estimated measuring fat skinfolds (25), with the help of a caliper (Lange, USA). Anaerobic power was evaluated by using free jumps, squat jumps (SJ) and counter-movement jumps (CMJ), according to previously published protocols (26). Speed was also assessed in 20 meters using validated sprint tests (27). Aerobic power was evaluated using the 2-km track test on an elliptical running track. The run was timed using a Q\&Q digital stopwatch (Casio, HS80TW, China), and the maximum oxygen consumption(VO2max) was calculated as described before (28).

Both aerobic and anaerobic power results fed a cluster analysis that allowed us to classify athletes into two categories: endurance and powerful. Our group has used this model to characterize and address several issues in team sports $(29,30)$.

\subsection{Measurement of Biochemical Markers}

During the first week of the preseason, CPK and urea were measured on a daily basis (from 7 A.M. to 8 A.M., 5 straight days from Monday to Friday). The subjects were in a sitting position, with an 8-hour fasting period, before the training session. 4-mL venous blood samples were drawn, stored with heparin (BD Vacutainer, USA) and transported in a freezer. Then, they were centrifuged at $2000 \mathrm{~g}$ for 15 minutes to separate the plasma. CPK and urea were measured in a clinical laboratory within the next 2 hours by using an ERBA Chem 7 analyzer (Erba Mannheim, Germany).

During the preseason, these athletes stayed in a hotel located at $2125 \mathrm{~m}$ above sea level with an average temperature of $17^{\circ} \mathrm{C}$. They were given a progressive increase of physical workload, and they were guaranteed adequate nutrition and breaks during their training sessions. They remained under supervision of the medical staff and no recreational physical activities were allowed. During the 
next 19 weeks, when the football players participated in the national football league, CPK and urea were measured at a mean of $54.6 \pm 11.8$ hours before each competition, always from 7 A.M. to 8 A.M. (Figure 1). During this period, all subjects were instructed to avoid any moderate or highintensity physical activity besides those scheduled by the team staff.

\subsection{Quantification of Training Load}

Training loads (TL) were measured bearing in mind intensity and volume in both training and competition sessions. Briefly, the football team physical trainer scored the intensity(IS) using a 1 to 5 scale. A IS equal to 1 reflects a resting day, and an IS amounting 5 indicates a day of a high intensity. The IS of all sessions during the week were then averaged to give a weekly IS (wIS). The durations of daily sessions were pooled to give the total time of work per week in minutes (wTIME), including warming-up. Then, wIS and wTIME values were used to calculate a weighted weekly training load (wTL) for each player, according to Equation 1 :

$w T L=w I S \times(w T I M E / M a x T I M E)$

Where MaxTIME is the maximum value of wTIME among the players during each week. wTL took values from 0 to 5.

\subsection{Evaluation of Sports and MI}

The sports medicine specialist in charge of the team was present at every practice session and football match. He recorded the date, location, type, and athletes' days of disability when injured, as suggested $(31,32)$. The MI was defined as the rupture of the fascia or muscle fibres detected during follow-up and the diagnosis was confirmed using ultrasound or nuclear magnetic resonance images, according to published protocols (33-35). Players were confirmed with a MI by a panel of experts, composed of three or four physicians according to the difficulty of each case: Two sports medicine specialists, a radiologist and an orthopaedic surgeon. Contusions and traumatisms were not taken into account when calculating the total of MI. For the statistical analysis, injured subjects were called group 1, and non-injured subjects were called group 2. Injury rate was calculated as the number of MI per 1000 hours of pooled training and match exposures.

\subsection{Statistical Analysis and Research Reporting Guideline}

No sample size was calculated for this study. For results, the description of nominal variables was done using percentages and ratios. Shapiro-Wilk's test was used to evaluate if the distribution of quantitative variables in the entire sample and in the various subgroups came from a population with a normal distribution. The description of demographic anthropometric and physical variables was done in accordance with the onset of MI during the weeks of follow-up. For quantitative variables with a normal distribution, the mean value and the standard deviation were reported. For qualitative variables with a distribution different from a normal distribution, the median and interquartile ranges were used, and the ratio of athletes with a MI was calculated.

Quantitative demographical, anthropometrical and physical characteristics were compared depending on the onset of a MI during follow-up with a Student's $t$-test or a Mann-Whitney U test depending on the type of distribution. Pearson's $\chi^{2}$ test was used for qualitative characteristics.

To compare CPKand urea values prior to a $\mathrm{MI}(4,3,2$ and one week before), with preseason values of injured football players, paired Student's $t$-tests or Wilcoxon tests were used depending on the type of distribution.

A mixed-effects model to estimate the effect of TL on CPK and urea levels was adjusted for BMI differences. For this, the natural logarithm of CPK(LnCPK) was used, due to its not normal, skewed distribution. The model includes a fixed component due to the effect of the independent variable (TL) and a randomized component given by the correlation among intra-player measurements. Adjustments for CPK levels were run when evaluating the TL-urea relationship. Adjustments for urea were run when evaluating the TL-LnCPK relationship. Z statistics and confidence intervals (CI 95\%) are shown. Analyses were conducted using SPSS V. 20.0 (IBM, USA) and STATA V. 14.0 (StataCorp, USA), assuming a 5\% statistical significance level. The STROBE guideline was used for this research report (36).

\section{Results}

Forty football players were eligible since they were male, training with the chosen football team. Nevertheless, 15 athletes were young athletes and 2 more were transferred to other teams. Finally, 23 professional players were included (Figure 2). There was no loss of subjects during follow-up. Their average age, BMI and percentage body fat were $25.3 \pm 4.2$ years, $24.7 \pm 1.5 \mathrm{Kg} / \mathrm{m}^{2}$ and $12.1 \pm 1.2$ $\%$, respectively. When the demographical, anthropometrical and physical characteristics were compared between groups 1 and 2, no differences were found (Table 1).

Group 1 included 9 subjects (39\% of total subjects) who underwent MI during follow-up. Hamstring injuries represented $66.6 \%$ of all MI. The injuries were as follows: five fascia injuries and one type-I hamstring MI, one fascia injury 


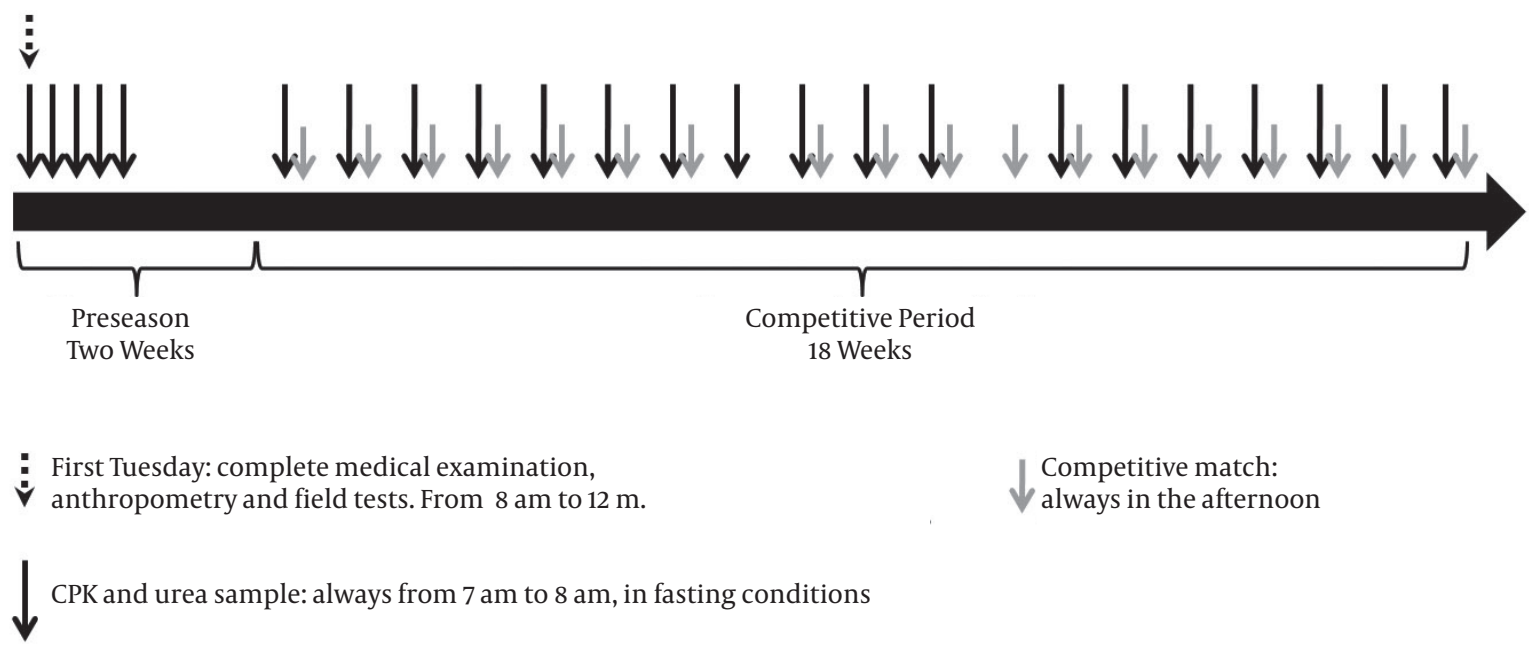

Figure 1. Complete protocol and study design. A total of 23 blood samples for CPK and urea measurements were drawn during preseason $(\mathrm{n}=5)$ and competitive period $(\mathrm{n}=$ 18) per player. During the competitive period the blood samples were obtained the previous day $(n=3)$, two days before $(n=13)$ or three days before $(n=1)$ the match. In one case, the sample was drawn a week after the last one even when no match was played thereafter.

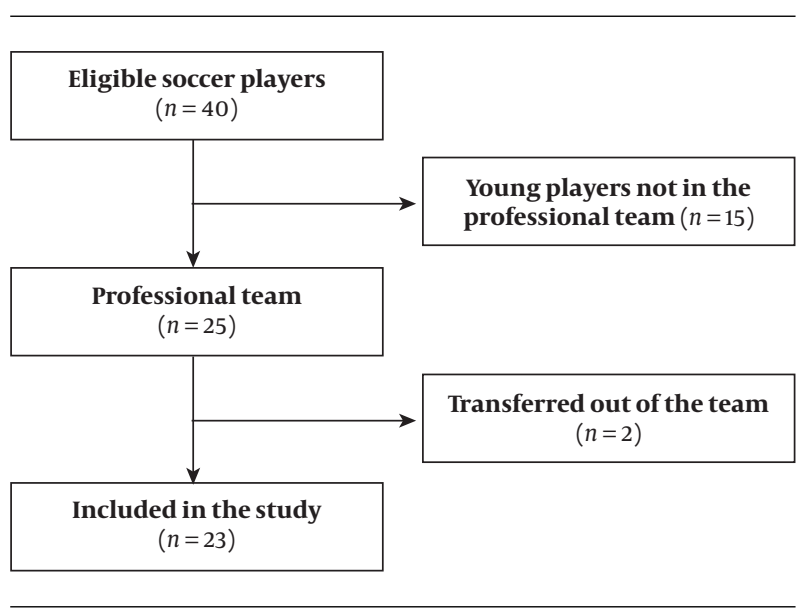

Figure 2. Flowchart showing the amount of soccer players eligible and finally included in the study

of the adductor muscle and two type-I injuries of the anterior rectus muscle. All MI became evident between weeks 9 and 20. Since the total of training and match exposure was 4059 hours, rates of 2.2 and 1.5 per 1000 hours of exposure were calculated for muscle and hamstring injuries, respectively.

No differences were observed when urea and CPK values obtained preseason were compared between groups (Table 2).

Football players having MI in follow-up showed an increase in biochemical markers 4 weeks before the onset of the injury (Table 3). Differences in CPK medians between the values for weeks 4,3 and 2 before the injury compared to preseason values ( $\mathrm{P}=0.018$ in all comparisons) were observed. There was a trend to be different for the value measured one week before MI compared to the preseason value $(\mathrm{P}=0.063)$. Likewise, the median of the urea was greater 2 weeks before the injury, in comparison with preseason values $(\mathrm{P}=0.043)$.

When analyzing the 9 injured athletes' individual CPK behavior, an increase of CPK values above the medians of the entire sample were noted within 4 weeks before the onset of the MI (Appendix 1A in Supplementary File) only in 5 of those players.

Likewise, when analyzing the behavior of the individual urea of the 9 injured athletes, an increase of urea values above the medians of the entire sample within 4 weeks prior to the onset of the injury (Appendix 1B in Supplementary File) was observed in 7 subjects.

The median values of CPK and urea showed peaks and valleys along the whole season. A temporal relationship between the kinetics of CPK, urea and the TL can be seen in Appendices $1 \mathrm{~A}$ - C in Supplementary File. A mixed-effects model was used to analyze this relationship. After adjusting for differences by CPK and BMI, a significant effect of TL on urea levels was found $(Z=2.85 ; \mathrm{P}<0.01)$. This means that for each one point increase in TL, urea levels increased by $0.97 \mathrm{mg} / \mathrm{dL}$ (CI 95\% 0.3 to 1.64). After adjusting for urea and BMI, a significant effect of TL on LnCPK was found (Z $=6.98 ; \mathrm{P}<0.01)$. For each one point increase in TL, LnCPK levels increased by 0.17 (CI 95\% 0.12 to 0.22 ). Individual predicted values of LnCPK and urea according to each TL in 


\begin{tabular}{|c|c|c|c|}
\hline Variables & Group $1(N=9)$ & Group $2(N=14)$ & P Value \\
\hline $\operatorname{Age}(y)$ & $25.8 \pm 4.4$ & $25.1 \pm 4.3$ & $0.709^{\mathrm{b}}$ \\
\hline Race & & & $0.962^{\mathrm{c}}$ \\
\hline White & 33.3 & 28.6 & \\
\hline Black & 44.4 & 50.0 & \\
\hline Mestizo & 22.2 & 21.4 & \\
\hline Player position & & & $0.304^{c}$ \\
\hline Goalkeeper & 11.1 & 7.1 & \\
\hline Defender & 0.0 & 28.6 & \\
\hline Lateral & 22.2 & 21.4 & \\
\hline Midfielder & 55.6 & 21.4 & \\
\hline Forward & 11.1 & 21.4 & \\
\hline $\operatorname{BMI}\left(\mathrm{kg} / \mathrm{m}^{2}\right)$ & $24.7 \pm 1.4$ & $24.8 \pm 1.7$ & $0.827^{b}$ \\
\hline Body fat (\%) & $12.4 \pm 1.0$ & $11.9 \pm 1.4$ & $0.373^{\mathrm{b}}$ \\
\hline Resting heart rate (bpm) & $59.2 \pm 4.0$ & $56.0 \pm 7.1$ & $0.258^{\mathrm{b}}$ \\
\hline Resting systolic pressure (mmHg) & $118.1 \pm 9.4$ & $122.1 \pm 7.6$ & $0.290^{\mathrm{b}}$ \\
\hline Resting diastolic pressure (mmHg) & $75.4 \pm 7.4$ & $75.9 \pm 5.5$ & $0.868^{\mathrm{b}}$ \\
\hline Squat jump (cm) & $56.6 \pm 7.1$ & $54.7 \pm 3.3$ & $0.438^{\mathrm{b}}$ \\
\hline Countermovement jump (cm) & $58.7 \pm 8.0$ & $56.2 \pm 4.0$ & $0.357^{\mathrm{b}}$ \\
\hline Vertical jump (cm) & $70.4 \pm 9.3$ & $65.1 \pm 5.3$ & $0.126^{\mathrm{b}}$ \\
\hline 20 m sprint test (dash) $(s)$ & $3.0 \pm 0.2$ & $3.1 \pm 0.1$ & $0.228^{\mathrm{b}}$ \\
\hline $\operatorname{Speed}(\mathbf{m} / \mathbf{s})$ & $6.6 \pm 0.3$ & $6.4 \pm 0.3$ & $0.211^{\mathrm{b}}$ \\
\hline $20 \mathrm{~m}$ fly sprint test (s) & $2.3 \pm 0.1$ & $2.4 \pm 0.1$ & $0.116^{\mathrm{b}}$ \\
\hline $\operatorname{Speed}(\mathbf{m} / \mathbf{s})$ & $8.7 \pm 0.4$ & $8.4 \pm 0.4$ & $0.100^{\mathrm{b}}$ \\
\hline Maximum oxygen consumption (mL/kg.min) & $56.2 \pm 3.3$ & $56.0 \pm 3.4$ & $0.911^{\mathrm{b}}$ \\
\hline Classification according to the physical condition (\%) & & & $0.806^{\mathrm{c}}$ \\
\hline Endurance & 37.5 & 42.9 & \\
\hline Powerful & 62.5 & 57.1 & \\
\hline
\end{tabular}

Abbreviations: BMI, body mass index; MI, muscle injuries.

${ }^{\mathrm{a}}$ Values are expressed as mean $\pm \mathrm{SD}$.

${ }^{\mathrm{b}}$ Student's $t$-test.

cPearson's Chi-squared test.

each player are shown in Figure 3. To further explore that relationship, we analyzed the changes in urea and LnCPK in groups 1 and 2. Two interesting situations arose. Firstly, in injured players for each point increase in TL, four weeks before the injury, urea increased by $5.5 \mathrm{mg} / \mathrm{dL}$ (CI 95\% 0.51 $11.6, Z=1.8 ; P=0.073)$, while in non-injured players for each point increase in TL, urea increased by $1.2 \mathrm{mg} / \mathrm{dL}$ (CI 95\% 0.4 - 2.0, $Z=2.92 ; \mathrm{P}<0.01)$. Secondly, for each point increase in TL, LnCPK increased by 0.19 (CI 95\% $0.11-0.27, Z=4.49$; P $<0.01$ ) in injured players, while an increase of 0.16 (CI 95\% $0.10-0.22, \mathrm{Z}=5.49 ; \mathrm{P}<0.01$ ) was found in non-injured players. We did not find a significant effect of TL on LnCPK when evaluating the 4 weeks before the injury.

\section{Discussion}

The most important new findings of this work are the following: (1) Biochemical markers CPK and urea increase weeks prior to the establishment of a clinically evident MI in football players (Table 3); (2) this increase can be reliably identified if individual profiles for CPK and urea are constructed during both preseason and the whole competitive season; and (3) a mixed-effects model allowed us to estimate urea and CPK values in football players (Figure 3).

\subsection{Pathophysiological Aspects and Limitations of the Classical Use of CPK and Urea as Biochemical Markers}

Under different stimuli, sarcolemmal injury or altered intramuscular energy status is associated with increased 


\begin{tabular}{|c|c|c|c|c|c|c|c|}
\hline \multirow{2}{*}{ Preseason Measurements } & \multicolumn{3}{|c|}{ Group $1(N=9)$} & \multicolumn{3}{|c|}{ Group $2(N=14)$} & \multirow{2}{*}{ PValue $^{\mathbf{a}}$} \\
\hline & Median & P25 & P75 & Median & P25 & P75 & \\
\hline CPK 1, 29th Jun & 213.0 & 169.5 & 320.0 & 238.5 & 170.8 & 382.8 & 0.600 \\
\hline CPK 2, 30th Jun & 389.0 & 294.0 & 531.5 & 465.0 & 303.0 & 572.3 & 0.440 \\
\hline CPK 3, 1st Jul & 409.0 & 255.0 & 1474.0 & 579.0 & 318.5 & 765.0 & 0.650 \\
\hline CPK 4, 2nd Jul & 405.5 & 248.3 & 1857.0 & 478.0 & 430.5 & 928.0 & 0.579 \\
\hline CPK 5, 3rd Jul & 405.0 & 268.5 & 1623.0 & 513.0 & 350.0 & 752.0 & 0.765 \\
\hline Urea 1, 29th Jun & 34.1 & 28.8 & 42.2 & 32.9 & 28.7 & 34.6 & 0.477 \\
\hline Urea 2, 30th Jun & 41.9 & 39.6 & 47.1 & 36.2 & 35.5 & 41.4 & 0.055 \\
\hline Urea 3, 1st Jul & 38.3 & 34.6 & 41.7 & 34.8 & 32.5 & 40.0 & 0.261 \\
\hline Urea 4, 2nd Jul & 39.2 & 33.4 & 44.7 & 38.3 & 34.9 & 42.9 & 1.000 \\
\hline Urea 5, 3rd Jul & 41.5 & 35.0 & 42.8 & 37.5 & 35.9 & 42.0 & 0.765 \\
\hline
\end{tabular}

Abbreviations: CPK, creatine phosphokinase; MI, muscle injuries.

${ }^{\mathrm{a}}$ Mann-Whitney U test.

Table 3. Comparison Between CPK $(\mu \mathrm{mol} / \mathrm{L})$ and Urea $(\mathrm{mg} / \mathrm{dL})$ Values Measured 4,3, 2 and 1 Week Before a MI with the Median Preseason Values in the 9 Injured Football Players (Group 1)

\begin{tabular}{|c|c|c|c|c|}
\hline Variable, Group $1(\mathrm{~N}=9)$ & Median & P25 & P75 & PValue $^{\mathbf{a}}$ \\
\hline CPK preseason $^{\mathbf{b}}(\mu \mathrm{mol} / \mathrm{L})$ & 226.0 & 182.0 & 332.0 & - \\
\hline CPK 4 weeks before MI & 280.5 & 239.0 & 391.0 & 0.018 \\
\hline СРК 3 weeks before MI & 294.0 & 222.0 & 509.0 & 0.018 \\
\hline CPK 2 weeks before MI & 248.0 & 196.0 & 482.0 & 0.018 \\
\hline CPK 1 weeks before MI & 330.0 & 152.0 & 831.8 & 0.063 \\
\hline Urea preseason $^{\mathbf{b}}(\mathrm{mg} / \mathrm{dL})$ & 32.9 & 28.8 & 37.3 & - \\
\hline Urea 4 weeks before MI & 37.0 & 30.4 & 41.4 & 0.917 \\
\hline Urea 3 weeks before MI & 36.1 & 30.6 & 46.5 & 0.735 \\
\hline Urea 2 weeks before MI & 40.9 & 37.2 & 43.5 & 0.043 \\
\hline Urea 1 weeks before MI & 39.0 & 36.5 & 45.0 & 0.236 \\
\hline
\end{tabular}

Abbreviations: CPK, creatine phosphokinase; MI, muscle injuries.

${ }^{a}$ Wilcoxon test, difference in medians when compared to the preseason levels.

${ }^{\mathrm{b}}$ These values are the means or medians of the five preseason values of the 9 injured subjects.

membrane permeability or its complete rupture and release of several cytoplasmic soluble factors such as CPK. From the pathophysiological point of view, it would be reasonable to think that the amount of CPK released would be proportional to the degree of muscle damage $(17,18,21$, $37,38)$. Then, muscle mini-lesions and inadequate recovery may explain small increases in CPK prior to the establishment of larger, clinically evident MI. However, such a relationship with clinical implications for a given population (i.e. football players, runners, etc.), has not been clearly established. This explains the lack of reference values for diagnosis of MI and the difficulty to find values for biochemical markers to establish the differences between a pathological state and a physiological one (20-22, 39). Actually, there is no current consensus because of the enormous individual variability of measured values for CPK and urea $(17,20,21,39)$, hindering the use of CPK and urea as predictors of muscle damage. Professional Colombian foot- ball players were not exempt of this variability. The values we found at the preseason are difficult to interpret in light of those published in the literature. They were even difficult to interpret when compared with the medians of the group they were taken from. For instance, only 5 out of the 9 injured athletes showed CPK values at the weeks before the lesion that were higher than the median of the group of 23 athletes. The other 4 always had values lower than the median of the whole group. The same applies for urea measurements (Appendix 1 in Supplementary File). Our results show that there are peaks and valleys during the season, as expected $(21,39,40)$, with some median values of all subjects being higher than the higher normal range reported for CPK in healthy people. Using median values for our population would have generated at some moment a classification of the whole cohort as abnormal. Then, to decide what conduct should be appropriate for these athletes would be puzzling. 
A

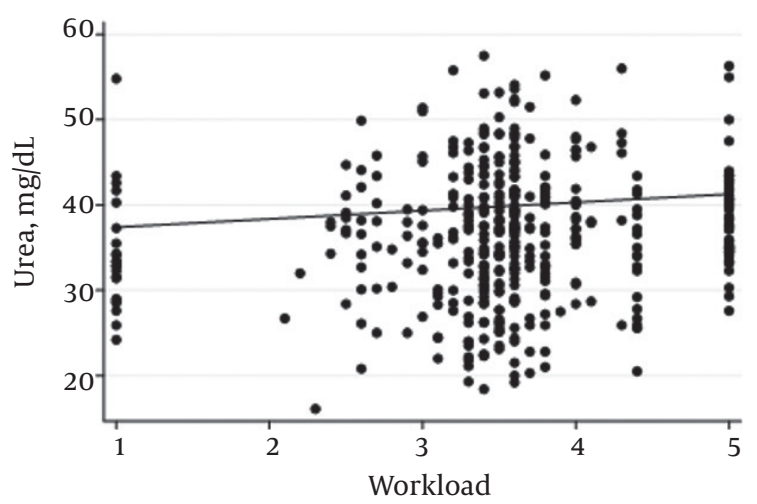

B

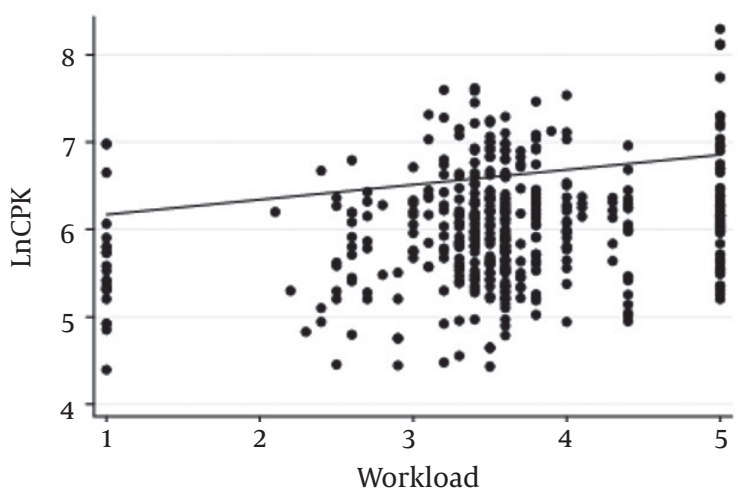

Figure 3. Scatterplot of predicted values for urea (mg/dL, A), and LnCPK (dimensionless, B) according to training load. A, Urea values were adjusted for body mass index and LnCPK values. B, LnCPK values were adjusted for body mass index and urea values. Each dot represents a single training session of each player. The solid lines indicate the fits to the points.

\subsection{New Approach to the Use of CPK and Urea in Biochemical Control: Practical Implications in Football}

Our rates and locations of MI were similar to those reported in other studies (1-3). Primary prevention ought to be the main strategy to reduce the onset of MI. Repeated biochemical marker measurements during training sessions could detect muscle tissue subclinical alterations prior to the onset of tissue damage $(6,21)$. Actually, in the athletic field, CPK and urea have been used as established muscle overload and injury markers $(20,21)$, but the behavior of these markers prior to MI was unknown. In this study, we found that CPK and urea values increased within several weeks prior to the onset of a MI, when compared to preseason values, not against published reference values or actual central tendency values. Hence, we consider that a weekly measurement of CPK and urea, when compared to well characterized values established before starting the season could be used as a subclinical muscle damage marker and as a professional football player's MI predictor and prevention tool. Then it is tempting to propose the establishment of a biochemical passport, in analogy to the biological passport employed in other contexts, to follow CPK and urea values in athletes from different sports during several seasons. So, following CPK and urea values to be compared to both preseason own values and to expected increases according to the TL (as in our mixedeffects model) could help us reduce the incidence of MI. The latter would come by means of the reduction of the load that could be applied specifically to the athlete that starts showing abnormal biochemical values. These hypotheses and their clinical impact could be tested in a future, multicentric work.
Several papers dealing with repetitive measurements of CPK and urea in athletes have been published $(20,21)$. These measurements were used as markers of overtraining or muscle overload, but not as predictors of MI. In one work the authors decreased the load of the football players enrolled in their study upon finding high CPK values, but one subject who did not reduce their workload became injured (21). In our case, the subjects with sustained higher values were given a lesser load in the next training session; however, this was based on the experience of the staff, since not a pre-established protocol was followed. Our results showed that this intervention did not avoid the appearance of the MI. Then, it is a pending task to establish a protocol to follow when the players show sustained higher values compared to their preseason ones.

Persistent high CPK values in athletes might be related to a silent myopathy. This condition cannot explain our results since our athletes were normal at the physical examination, with no history suggesting a muscle disease, the preseason CPK values were considered normal and they were not persistently high in any of the players, instead, always showed a curve with peaks and valleys. In the same way, since neither a reduction in strength or performance nor sleep disorders nor urine color changes, nor gastrointestinal disturbances, nor other complaints were found in our athletes, we can rule out that the observed values were associated with overreaching/overtraining conditions (20), or episodes of rhabdomyolysis (18). Drug consumption is not expected to be associated with increased $\mathrm{CPK}$ values in our athletes, however, cannot be completely ruled out since no toxicological tests were run to evaluate this. 


\subsection{Strengths and Weaknesses}

The main strengths of our work are the following: (1) A follow-up of a team during whole preseason and season with a total of 23 CPK and urea measurements obtained from a daily to weekly basis with standardized times and conditions was carried out. Moreover, the measurements during a season were not performed with a descriptive emphasis, as previously done $(37,39)$, but to relate them to an outcome with impact in football player's health. (2) A reliable recording and diagnosis of MI, because we had a well prepared, expert, medical staff. (3) We controlled the load and constructed a robust model to relate the individualised load to the CPK and urea values. (4)The results may be generalizable to adult, male professional football players. The main weaknesses are: (1) Multiple comparisons were made and this may increase the likelihood of a type I error. (2) We did not calculate a sample size so we are not sure of the actual power of the study. (3) The sample size may be small for the outcome, which increases the likelihood of a type II error. For instance, a limited sample and amount of MI may have affected the power to find statistically significant differences between CPK values one week before the MI and the preseason values $(P=0.063$, Table 3 ). Since the squads' size is increasing (2), and multicentric studies are common, a more powerful study could be carried out now to address these limitations. (4) The impossibility of controlling the subjects outside the team facilities during the competitive season. (5) The results may not be generalizable to female or sub elite football players. (6) Several intrinsic and extrinsic factors involved in sports injuries were not fully controlled. However, this may have not affected our results since: Demographic, anthropometric and physical performance variables were not different between injured and non-injured players, as shown in Table 1, the mixed-effects model was adjusted by BMI, and most of the non-controlled risk factors are expected to be the same for all players: soccer field type, weather, level of skill and gender. (7) Our results should not be understood as to show a cause-effect relationship between biochemical markers and MI, instead, they show an association between these variables which have implications in the sports medicine practice.

\subsection{Conclusion}

Variability in CPK and urea values seen among professional football players limits the use of cross-sectional reference values in training control and MI prevention. So, individualized follow-up taking into account both preseason and season values, may help overcome this limitation. In this study we showed that CPK and urea plasmatic values significantly increased within 4 weeks prior to the onset of a MI, when compared to preseason values. Thus, measuring biochemical markers and constructing a personal biochemical passport may identify individual reference values with implications for MI diagnosis and prevention. These values would be indicators of athletes' adaptations to physical workloads and keeping the subject within their own ranges would work as a strategy to prevent the onset of MI. This should be implemented with other strategies known to reduce sports injuries incidence and could also be tested in other sports disciplines with high MI incidence (41). These results may favor a more coherent use of some biochemical markers in sports medicine practice.

\section{Supplementary Material}

Supplementary material(s) is available here [To read supplementary materials, please refer to the journal website and open PDF/HTML].

\section{Acknowledgments}

We want to thank the executives, medical staff, coach and players from Corporación Deportiva Independiente Medellín S.A, Medellín, Colombia, for help during this research.

\section{Footnotes}

Authors' Contribution: Juan J Osorio and Edgar A Méndez collected and analyzed data, Jorge Osorio-Ciro obtained funds and analyzed data, Daniel Aguirre-Acevedo advised on the statistical analysis, Juan C Calderón and Jaime A Gallo-Villegas wrote the project, obtained bioethics approval, analyzed data and drafted the manuscript. All authors approved the final version submitted.

Conflict of Interests: All authors declare that they do not have any conflicts of interests.

Ethical Considerations: All procedures involving humans in this study were in accordance to the 1964 Declaration of Helsinki and the Resolution number 8430 of 1993 by the National Ministry of Health of Colombia, and were approved by the Bioethics Committee of the University of Antioquia, Colombia (minutes 004 from March 2017). No informed consent was obtained because it is not required for this type of study. The ethical approval for this research can be found at: www.udea.edu.co/physis. The ethical code can be found at: http://www.udea.edu.co/wps/ portal/udea/web/inicio/investigacion/etica-en-lainvestigacion-udea/contenido/ascontenidosmenu/comitecentral-etica-investigacion.

Funding/Support: This work was funded by Corporación Deportiva Independiente Medellín (private institution) 
and University of Antioquia (public institution), Medellín, Colombia. Funders paid samples transportation, biochemical tests and salaries of researchers, but did not participate in data collection and analysis, article writing or submission.

\section{References}

1. Dauty M, Collon S. Incidence of injuries in French professional soccer players. Int J Sports Med. 2011;32(12):965-9. doi: 10.1055/s-0031-1283188. [PubMed: 22052029].

2. Ekstrand J, Walden M, Hagglund M. Hamstring injuries have increased by $4 \%$ annually in men's professional football, since 2001 A 13-year longitudinal analysis of the UEFA Elite Club injury study. Br J Sports Med. 2016;50(12):731-7. doi: 10.1136/bjsports-2015-095359. [PubMed: 26746908].

3. Ekstrand J, Hagglund M, Walden M. Epidemiology of muscle injuries in professional football (soccer). Am J Sports Med. 2011;39(6):1226-32. doi: 10.1177/0363546510395879. [PubMed: 21335353].

4. Junge A, Dvorak J. Injury surveillance in the World Football Tournaments 1998-2012. Br J Sports Med. 2013;47(12):782-8. doi: 10.1136/bjsports-2013-092205. [PubMed: 23632746]. [PubMed Central: PMC3717759].

5. Junge A, Dvorak J. Football injuries during the 2014 FIFA World Cup. BrJ Sports Med. 2015;49(9):599-602. doi:10.1136/bjsports-2014-094469. [PubMed: 25878077]. [PubMed Central: PMC4413685]

6. Volpi P, Taioli E. The health profile of professional soccer players: Future opportunities for injury prevention. J Strength Cond Res. 2012;26(12):3473-9. doi: 10.1519/JSC.0b013e31824e195f. [PubMed: 22344052]

7. Ekstrand J, Healy JC, Walden M, Lee JC, English B, Hagglund M. Hamstring muscle injuries in professional football: The correlation of MRI findings with return to play. Br J Sports Med. 2012;46(2):112-7. doi: 10.1136/bjsports-2011-090155. [PubMed: 22144005].

8. Gomes Neto M, Conceicao CS, de Lima Brasileiro AJA, de Sousa CS, Carvalho VO, de Jesus FLA. Effects of the FIFA 11 training program on injury prevention and performance in football players: A systematic review and meta-analysis. Clin Rehabil. 2017;31(5):651-9. doi: 10.1177/0269215516675906. [PubMed: 27811329].

9. McCall A, Davison M, Andersen TE, Beasley I, Bizzini M, Dupont G, et al. Injury prevention strategies at the FIFA 2014 World Cup: Perceptions and practices of the physicians from the 32 participating national teams. BrJ Sports Med. 2015;49(9):603-8. doi: 10.1136/bjsports2015-094747. [PubMed: 25878078]. [PubMed Central: PMC4413740].

10. Parkkari J, Kujala UM, Kannus P. Is it possible to prevent sports injuries? Review of controlled clinical trials and recommendations for future work. Sports Med. 2001;31(14):985-95. doi: 10.2165/00007256200131140-00003. [PubMed: 11735682].

11. Thorborg K, Krommes KK, Esteve E, Clausen MB, Bartels EM, Rathleff MS. Effect of specific exercise-based football injury prevention programmes on the overall injury rate in football: A systematic review and meta-analysis of the FIFA 11 and 11+ programmes. BrJ Sports Med. 2017;51(7):562-71. doi: 10.1136/bjsports-2016-097066. [PubMed: 28087568]

12. Banfi G, Colombini A, Lombardi G, Lubkowska A. Metabolic markers in sports medicine. Adv Clin Chem. 2012;56:1-54. [PubMed: 22397027].

13. Brancaccio P, Lippi G, Maffulli N. Biochemical markers of muscular damage. Clin Chem Lab Med. 2010;48(6):757-67. doi: 10.1515/CCLM.2010.179. [PubMed: 20518645].

14. Guerrero M, Guiu-Comadevall M, Cadefau JA, Parra J, Balius R, Estruch A, et al. Fast and slow myosins as markers of muscle injury. Br J Sports Med. 2008;42(7):581-4. discussion 584. doi: 10.1136/bjsm.2007.037945. [PubMed: 18070807]. [PubMed Central: PMC2564766].
15. Shen YQ, Tang L, Zhou HM, Lin ZJ. Structure of human muscle creatine kinase. Acta Crystallogr D Biol Crystallogr. 2001;57(Pt 8):1196-200. [PubMed: 11517911].

16. Wallimann $T$, Dolder $M$, Schlattner U, Eder M, Hornemann $T$, O'Gorman E, et al. Some new aspects of creatine kinase (CK): Compartmentation, structure, function and regulation for cellular and mitochondrial bioenergetics and physiology. Biofactors. 1998;8(3-4):22934. [PubMed: 9914824].

17. Brancaccio P, Maffulli N, Limongelli FM. Creatine kinase monitoring in sport medicine. Br Med Bull. 2007;81-82:209-30. doi: 10.1093/bmb/ldm014. [PubMed: 17569697].

18. Zutt R, van der Kooi AJ, Linthorst GE, Wanders RJ, de Visser M. Rhabdomyolysis: Review of the literature. Neuromuscul Disord. 2014;24(8):651-9. doi: 10.1016/j.nmd.2014.05.005. [PubMed: 24946698].

19. Machado M, Koch AJ, Willardson JM, Pereira LS, Cardoso MI, Motta MK, et al. Effect of varying rest intervals between sets of assistance exercises on creatine kinase and lactate dehydrogenase responses. J Strength Cond Res. 2011;25(5):1339-45. doi: 10.1519/JSC.ob013e3181d680d6. [PubMed: 20926967]

20. Hartmann U, Mester J. Training and overtraining markers in selected sport events. Med Sci Sports Exerc. 2000;32(1):209-15. [PubMed: 10647551].

21. Lazarim FL, Antunes-Neto JM, da Silva FO, Nunes LA, BassiniCameron A, Cameron LC, et al. The upper values of plasma creatine kinase of professional soccer players during the Brazilian National Championship. J Sci Med Sport. 2009;12(1):85-90. doi: 10.1016/j.jsams.2007.10.004. [PubMed: 18069060].

22. Mougios V. Reference intervals for serum creatine kinase in athletes.BrJSports Med.2007;41(10):674-8. doi:10.1136/bjsm.2006.034041. [PubMed: 17526622]. [PubMed Central: PMC2465154].

23. Rahnama N, Faramarzi M, Gaeini AA. Effects of intermittent exercise on cardiac troponin I and creatine Kinase-MB. Int J Prev Med. 2011;2(1):20-3. [PubMed: 21448400]. [PubMed Central: PMC3063467].

24. Heled Y, Bloom MS, Wu TJ, Stephens Q, Deuster PA. CK-MM and ACE genotypes and physiological prediction of the creatine kinase response to exercise. J Appl Physiol (1985). 2007;103(2):504-10. doi: 10.1152/japplphysiol.00081.2007. [PubMed:17478608].

25. Carter L, Yuhasz M. Skinfolds and body composition of Olympic athletes. In: Jokl E, Hebbelinck M, editors. Physical structure of the Olympic athletes Part II: Kinanthropometry of Olympic athletes. Karger; 1984. p. 144-82.

26. Komi PV, Bosco C. Utilization of stored elastic energy in leg extensor muscles by men and women. Med Sci Sports. 1978;10(4):261-5. [PubMed: 750844].

27. Hopker JG, Coleman DA, Wiles JD, Galbraith A. Familiarisation and reliability of sprint test indices during laboratory and field assessment. J Sports Sci Med. 2009;8(4):528-32. [PubMed: 24149593]. [PubMed Central: PMC3761528].

28. Diaz D, Valbuena L, Perez J, Cardona O. [Correlation between ergospirometry and the 2000 meter test]. Rev Ant Med Dep. 2000;3:1720. Spanish

29. Ospina Uribe CF, Gallo Villegas JA, Aguirre Acevedo-Acevedo DC, Balparda Arias JK, Aristizabal Ocampo JD. [Differences in the hemodynamic and autonomic response to sympathetic stress among powerful and resilient professional soccer players: A crosssectional study]. Apunt Med Esport. 2014;49(184):113-22. Spanish. doi: 10.1016/j.apunts.2014.06.004.

30. Vega G, Arrieta D, Cardona O, Estrada-Castrillon M, Narvaez-Sanchez $\mathrm{R}$, Calderon JC, et al. A new method for classifying athletes between powerful and endurance: Physiological variables that explain their different performance in field tests. Br J Sports Med. 2016;50(Suppl 1):A22-3. doi: 10.1136/bjsports-2016-097120.38.

31. Fuller CW, Ekstrand J, Junge A, Andersen TE, Bahr R, Dvorak J, et al. Consensus statement on injury definitions and data collection procedures in studies of football (soccer) injuries. Scand $J$ 
Med Sci Sports. 2006;16(2):83-92. doi: 10.1111/j.1600-0838.2006.00528.x. [PubMed: 16533346].

32. Junge A, Dvorak J, Graf-Baumann T, Peterson L. Football injuries during FIFA tournaments and the Olympic Games, 1998-2001: Development and implementation of an injury-reporting system. Am J Sports Med. 2004;32(1 Suppl):80S-9S. doi: 10.1177/0363546503261245. [PubMed: 14754863].

33. Ahn JM, El-Khoury GY. Role of magnetic resonance imaging in musculoskeletal trauma. Top Magn Reson Imaging. 2007;18(3):155-68. doi: 10.1097/RMR.ob013e318093e670. [PubMed: 17762380].

34. Douis H, Gillett M, James SL. Imaging in the diagnosis, prognostication, and management of lower limb muscle injury. Semin Musculoskelet Radiol. 2011;15(1):27-41. doi: 10.1055/s-0031-1271957. [PubMed: 21332018].

35. Torriani M, Kattapuram SV. Musculoskeletal ultrasound: An alternative imaging modality for sports-related injuries. Top Magn Reson Imaging. 2003;14(1):103-11. [PubMed: 12606872].

36. von Elm E, Altman DG, Egger M, Pocock SJ, Gotzsche PC, Vandenbroucke JP, et al. Strengthening the reporting of observational studies in epidemiology (STROBE) statement: Guidelines for reporting observational studies. BMJ. 2007;335(7624):806-8. doi: 10.1136/bmj.39335.541782.AD. [PubMed: 17947786]. [PubMed Central:
PMC2034723].

37. Silva JR, Rebelo A, Marques F, Pereira L, Seabra A, Ascensao A, et al. Biochemical impact of soccer: An analysis of hormonal, muscle damage, and redox markers during the season. Appl Physiol Nutr Metab. 2014;39(4):432-8. doi: 10.1139/apnm-2013-0180. [PubMed: 24669984].

38. Volfinger L, Lassourd V, Michaux JM, Braun JP, Toutain PL. Kinetic evaluation of muscle damage during exercise by calculation of amount of creatine kinase released. Am J Physiol. 1994;266(2 Pt 2):R434-41. doi: 10.1152/ajpregu.1994.266.2.R434. [PubMed: 8141400].

39. Meyer T, Meister S. Routine blood parameters in elite soccer players. Int J Sports Med. 2011;32(11):875-81. doi: 10.1055/s-0031-1280776. [PubMed: 22020850].

40. Djaoui L, Diaz-Cidoncha Garcia J, Hautier C, Dellal A. Kinetic postmatch fatigue in professional and youth soccer players during the competitive period. Asian J Sports Med. 2016;7(1). e28267. doi: 10.5812/asjsm.28267. [PubMed: 27217927]. [PubMed Central: PMC4870820].

41. Edouard P, Branco P, Alonso JM. Muscle injury is the principal injury type and hamstring muscle injury is the first injury diagnosis during top-level international athletics championships between 2007 and 2015. BrJSports Med.2016;50(10):619-30. doi:10.1136/bjsports-2015095559. [PubMed: 26887415]. 